\title{
BMJ Open Outcome of the 2016 United States presidential election and the subsequent sex ratio at birth in Canada: an ecological study
}

\author{
Ravi Retnakaran (D) , ${ }^{1,2,3}$ Chang Ye ${ }^{1}$
}

To cite: Retnakaran R, Ye C. Outcome of the 2016 United States presidential election and the subsequent sex ratio at birth in Canada: an ecological study. BMJ Open 2020;10:e031208. doi:10.1136/ bmjopen-2019-031208

- Prepublication history and additional material for this paper are available online. To view these files, please visit the journal online (http://dx.doi. org/10.1136/bmjopen-2019031208).

Received 22 April 2019 Revised 08 January 2020 Accepted 09 January 2020

Check for updates

(c) Author(s) (or their employer(s)) 2020. Re-use permitted under CC BY-NC. No commercial re-use. See rights and permissions. Published by BMJ.

${ }^{1}$ Leadership Sinai Centre for Diabetes, Mount Sinai Hospital, Toronto, Ontario, Canada

${ }^{2}$ Division of Endocrinology,

Department of Medicine,

University of Toronto, Toronto,

Ontario, Canada

${ }^{3}$ Lunenfeld-Tanenbaum

Research Institute, Mount

Sinai Hospital, Toronto, Ontario, Canada

Correspondence to Dr Ravi Retnakaran; ravi.retnakaran@ sinaihealthsystem.ca

\section{ABSTRACT}

Objectives The sex ratio at birth (proportion of boys to girls) generally shows slight male preponderance but may decrease in response to societal stressors. Discrete adverse events such as terrorist attacks and disasters typically lead to a temporary decline in the sex ratio 3-5 months later, followed by resolution over around 5 months thereafter. We hypothesised that the unexpected outcome of the 2016 US presidential election may have been a societal stressor for liberal-leaning populations and thereby precipitated such an effect on the sex ratio in Canada.

Design Ecological study.

Setting Administrative data for Ontario (Canada's most populous province).

Participants All births in Ontario from April 2010 to 0ct 2017 inclusive ( $n=1079758)$.

Primary and secondary outcome measures We determined the sex ratio at birth in Ontario for each month from April 2010 to 0ctober 2017 and performed segmented regression analysis to evaluate the seasonally adjusted sex ratio for the following three time periods: before the November 2016 election; after the election to before the anticipated impact; and from anticipated impact to 5 months thereafter.

Results In the 12 months following the election, the lowest sex ratio occurred in March 2017 (4 months post election). Compared with the preceding months, the sex ratio was lower in the 5 months from March to July $2017(p=0.02)$ during which time it was rising $(p=0.01)$, reflecting recovery from the nadir. Both effects were seen in liberal-leaning regions of Ontario (lower sex ratio $(p=0.006)$ and recovery $(p=0.002)$ in March-July 2017) but not in conservative-leaning areas $(p=0.12$ and $p=0.49$, respectively).

Conclusion The 2016 US presidential election preceded a temporary reduction in the sex ratio at birth in Canada, with the time course of changes therein matching the characteristic pattern of a discrete societal stressor.

\section{INTRODUCTION}

The human sex ratio at birth (ie, proportion of boys to girls) typically shows a slight male preponderance. ${ }^{1-3}$ Although its physiological determinants are not well understood, ${ }^{34}$ it is recognised that this ratio can

\section{Strengths and limitations of this study}

- This population-based study evaluated all births in Canada's most populous province for each month from April 2010 to October 2017, thereby enabling comprehensive assessment of the pattern of changes in the sex ratio in this population.

- The ecological study design enabled evaluation of this population outcome (sex ratio) and its precise monthly pattern in the year following the 2016 US presidential election, while accounting for seasonal changes therein.

- The ecological design with population-level data provides limited capacity for inference to the level of the individual and hence causality cannot be definitively ascertained.

- This population-based analysis cannot ascertain an individual woman's political preferences or whether her perception of the election outcome contributed to fetal loss and thereby impacted the sex ratio.

be modified by adverse societal conditions. As there is no conclusive evidence of variability in the sex ratio at conception, ${ }^{1}$ such variation in the analogous ratio at birth is believed to reflect sex-specific differences in the likelihood of fetal demise at various times during pregnancy. ${ }^{56}$ Indeed, adverse societal stressors such as natural and man-made disasters, ${ }^{7-10}$ economic downturn, ${ }^{11}$ social unrest, $^{10} 12$ and terrorist attacks ${ }^{10}{ }^{13-17}$ have all been reported to decrease the proportion of boys at birth, likely reflecting greater spontaneous loss of male fetuses in response to these conditions. ${ }^{5}{ }^{6}$ Notably, discrete events, such as terrorist attacks, have typically resulted in a temporary decline in the sex ratio 3-5 months after the event, followed by recovery over around 5 months thereafter. $^{1013-17}$ This pattern has been seen after a range of events, including the September 11, 2001 attacks, ${ }^{13-15}$ the 2004 Madrid bombings, ${ }^{10} 17$ the 2005 London bombings, ${ }^{10} 17$ the 2011 Norway attacks, ${ }^{16}$ and the 2012 Sandy 
Hook Elementary School shooting. ${ }^{16}$ Moreover, this characteristic pattern of the sex ratio in the months thereafter has been confirmed in a meta-analysis assessing the effect of these events on the sex ratio at birth. ${ }^{17}$

The outcome of the 2016 United States (US) presidential election on 8 November 2016 was perceived by most observers as a completely unexpected and stunning event, with unclear domestic and international ramifications that raised widespread societal concerns about the future. Given its global implications, we hypothesised that the unanticipated election of the nationalist right-leaning Republican nominee would be perceived by left-leaning populations outside the US as an adverse societal event and could thereby have affected the sex ratio in such countries. With its historically liberal society coupled with close geographical, economic, and socio-political ties to the US, Canada provides the prototypical example of such a country. Thus, in this context, we hypothesised that the outcome of the US presidential election on 8 November 2016 may have precipitated a temporary decline in the sex ratio at birth in Canada's most populous province (Ontario) 3-5 months later, and that this effect may relate to the political preferences of the population.

\section{METHODS}

The Better Outcomes Registry \& Network (BORN) collects comprehensive data on pregnancies and births in the province of Ontario. Through BORN, we obtained data on all births in Ontario from April 2010 to Oct 2017 ( $\mathrm{n}=1079758$ births). Specifically, we received the number of births (total and live births) and sex breakdown thereof (numbers of boys and girls, respectively) for each of the 91 months between April 2010 and Oct 2017 inclusive. As Ontario has 14 geographically distinct Local Health Integration Networks (LHINs) through which healthcare is delivered across the province, we obtained the same data stratified by LHIN of maternal residence. This study was approved by the Mount Sinai Hospital Research Ethics Board. All analyses were conducted using SAS 9.4 (SAS Institute, Cary, NC). The sex ratio at delivery was calculated as the ratio of males to females in each month from April 2010 to Oct 2017 inclusive. The time series of sex ratio thus comprised 91 timepoints. The analysis plan consisted of the following two steps: seasonal adjustment and segmented regression.

\section{Step 1: seasonal adjustment of sex ratio}

It is known that the sex ratio is subject to seasonality, ${ }^{10} 18$ therefore we used box plots of the time series of sex ratio by month to examine a possible seasonal pattern. An autoregressive integrated moving average (ARIMA) model-based seasonal adjustment method Tramo (time series regression with ARIMA noise, missing values and outliers) ${ }^{19} 20$ was implemented with PROC X12 in SAS to remove the seasonal component from the time series. ARIMA model is a generalisation of an autoregressive moving average (ARMA) model, which is a combination
Table 1 Crude (unadjusted) and seasonally adjusted sex ratio for all births in Ontario in each of the 12 months from November 2016 to October 2017

\begin{tabular}{|c|c|c|c|}
\hline & No of births & $\begin{array}{l}\text { Crude sex } \\
\text { ratio }\end{array}$ & $\begin{array}{l}\text { Seasonally- } \\
\text { adjusted } \\
\text { sex ratio }\end{array}$ \\
\hline Month & & (M:F) & (M:F) \\
\hline Nov 2016 & 11309 & 1.027792720 & 1.043159510 \\
\hline Dec 2016 & 11089 & 1.057710150 & 1.053889585 \\
\hline Jan 2017 & 11534 & 1.082701336 & 1.085020254 \\
\hline Feb 2017 & 10672 & 1.055865922 & 1.060867388 \\
\hline Mar 2017 & 11782 & 1.028232054 & 1.027164337 \\
\hline Apr 2017 & 11482 & 1.043787825 & 1.046988171 \\
\hline May 2017 & 12243 & 1.069822485 & 1.056590659 \\
\hline Jun 2017 & 12166 & 1.078592175 & 1.068903879 \\
\hline Jul 2017 & 12410 & 1.076987448 & 1.074560743 \\
\hline Aug 2017 & 12532 & 1.059152153 & 1.057795259 \\
\hline Sep 2017 & 12284 & 1.042227764 & 1.048025503 \\
\hline Oct 2017 & 11983 & 1.053641817 & 1.053431063 \\
\hline
\end{tabular}

of the AR (autoregressive) and MA (moving average) models. The approach consists of three stages: model identification, model estimation, and model diagnosis.

1. Model identification: we used Akaike's information criteria (AIC) to determine whether log transformation should be applied for the outcomes (sex ratios), and whether the corresponding additive mode or multiplicative model should be applied to decompose the seasonal component. Furthermore, the procedure identified the order for the unseasonal and seasonal autoregressive and moving average terms. A series of combinations of orders were generated and ranked in the order of Bayesian information criterion, so that the procedure determined a best-fitting ARIMA model $(0,1,1)(0,1,1)$ for our sex ratio series.

2. Model estimation: maximum likelihood method was used to estimate the seasonal component in the bestfitting ARIMA model so that the seasonal component could be removed from the time series and thereby enable determination of the seasonally adjusted time series.

3. Model diagnosis: residual analyses were conducted to check whether the identified model was appropriate, and Freidman and Kruskal-Wallis tests were performed to assess the presence of seasonality in the seasonally adjusted time series. Based on the seasonally adjusted time series of sex ratio, we determined when the lowest monthly sex ratio occurred in the year after the November 2016 election (table 1).

\section{Step 2: segmented regression analysis}

Segmented regression analysis was performed to estimate the potential impact of the US election on the sex ratio in Ontario in the months thereafter. This method is 


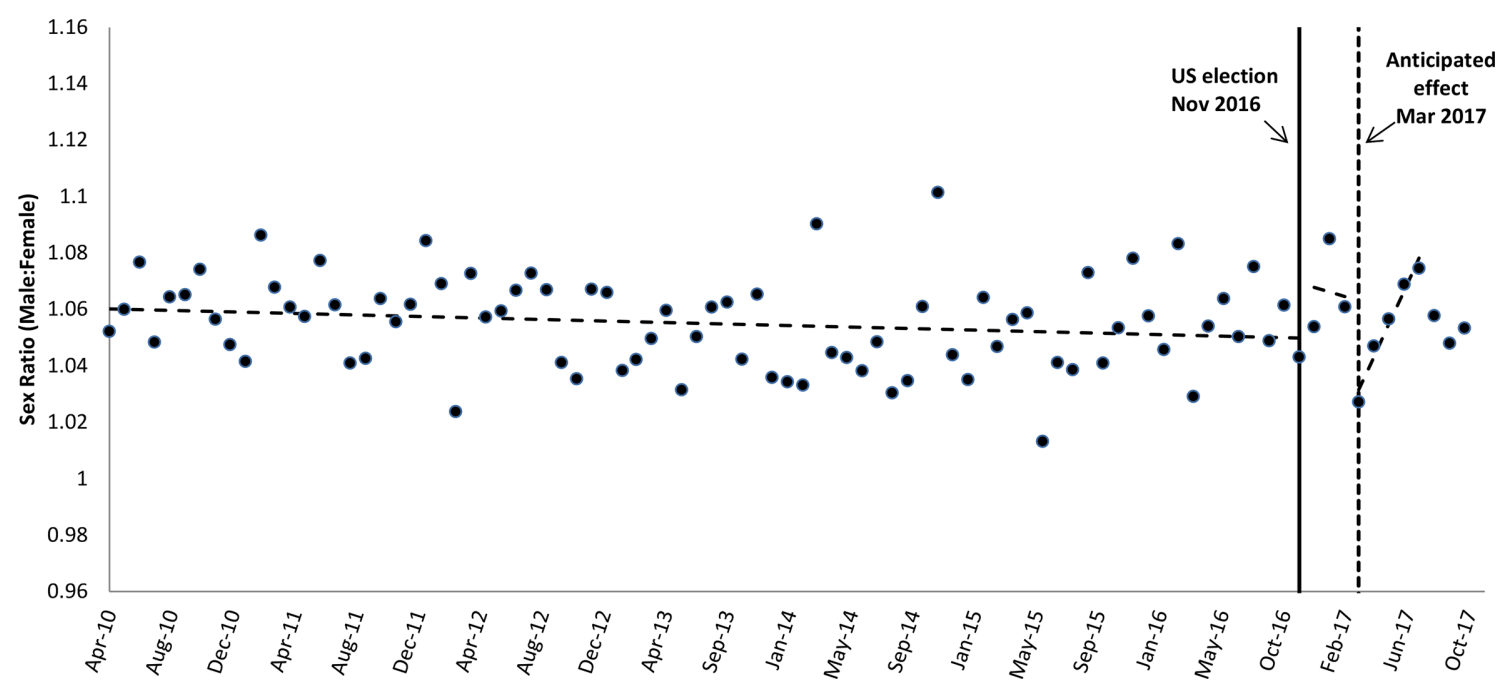

Figure 1 Time series of seasonally adjusted sex ratio by month from April 2010 to October 2017. The predicted regression line for the sex ratio is shown for the following three intervals: before election (from April 2010 to October 2016); period from election to before the anticipated effect (from November 2016 to February 2017); and the period from the anticipated effect to 5 months thereafter (from March to July 2017).

powerful in that it can control the trend effect of sex ratio (ie, to rule out the possibility that the observed decline in March 2017 was due to a downward trend over time); reduce measurement bias by ensuring concordance with population ratios rather than ratios at the LHIN/health region level; and allow stratification analysis to evaluate the potential differential impact of the event between different groups. ${ }^{21}$

The time series were divided into three segments: before the election (consisting of 79 months or timepoints from April 2010 to October 2016); the period from the election to before the anticipated effect (consisting of four timepoints from November 2016 to February 2017); and the period from the anticipated effect to the months thereafter (consisting of eight timepoints from March 2017 onwards). We constructed the segmented regression model in the form below, assuming linearity of the trend lines within each segment. We tested autocorrelation of residuals using the Durbin Watson statistic to confirm that the time series have no serious autocorrelations. Figure 1 presents the time series of the seasonally adjusted sex ratio by month from April 2010 to October 2017, with the predicted segmented regression line shown for the three segments. Since the decline in the sex ratio after a discrete adverse societal event is a transient phenomenon, we anticipated its presence for 5 months, as this was the time interval over which the sex ratio recovered from its nadir after the September 11, 2001 attacks $^{13}$ and the April 1992 Los Angeles riots. ${ }^{12}$ For this reason, the third interval in the segmented regression analyses ran from March 2017 to July 2017.

The segmented regression model was constructed as follows:

Seasonally - adjusted sex ratio $=\quad \beta 0+\beta 1 *$ time $+\beta 2 *$ event $+\beta 3 *$

time after event $+\beta 4 *$ effect +

$\beta 5 *$ time after effect + error term, where time is a continuous variable indicating time in months from the start of the observation period; event is an indicator taking a value of 0 before the election and 1 after the election; time after event is a continuous variable counting the number of months after the election, taking a value of 0 before the election and (time-80) after the election (which occurred at month 80); effect is an indicator taking a value of 0 before the anticipated effect occurred and 1 after the effect; time after effect is a continuous variable counting the number of months after the anticipated effect, taking a value of 0 before the effect and (time-83) after the effect, which occurred at month $84 ; \beta 0$ estimates the level of the sex ratio before election (baseline level), which is the level at the beginning of the pre-election period; $\beta 1$ estimates the change in sex ratio before the election, which is the slope of the trend before the election; $\beta 0+\beta 2$ estimates the level of the sex ratio after the election but before the anticipated effect occurred; $\beta 1+\beta 3$ estimates the change in sex ratio after the election but before the effect occurred; $\beta 0+\beta 2+\beta 4$ estimates the level of the sex ratio after the effect occurred; and $\beta 1+\beta 3+\beta 5$ estimates the change in sex ratio after the effect occurred.

In addition, we conducted stratification analyses using the same segmented regression model for the respective liberal-leaning and conservative-leaning areas of the province. To do so, we first classified each LHIN as either liberal leaning or conservative leaning based on the political party holding its constituent federal parliamentary ridings at the time of the US election in November 2016. Ridings were classified as liberal leaning if held by either the Liberal Party or the New Democratic Party. Ridings were classified as conservative leaning if held by the Progressive Conservative Party. Based on the political parties holding the respective federal parliamentary ridings comprising the geographical area of each 
LHIN, there were 11 liberal-leaning LHINs and three conservative-leaning LHINs in Ontario. Considering the unbalanced population of boys and girls at birth in each LHIN, we pooled the births across the three conservativeleaning LHINs and the 11 liberal-leaning LHINs, respectively, and then calculated the sex ratio for each of these two groups for each month. We repeated the ARIMA approach to obtain seasonally adjusted male and female series, and then calculated seasonally adjusted sex ratio series for both groups.

Finally, considering the limited data to fit the second line segment, we did two sensitivity analyses: with the exclusion of the second segment (by removing the data from December 2016 to February 2017); and with the aggregation of the first and second line segments, for the whole population and the respective liberal-leaning and conservative-leaning areas. The segmented regression model was then re-constructed as follows:

\section{Seasonally - adjusted sex ratio $=\beta 6+\beta 7 *$ time $+\beta 8 *$ effect $+\beta 9 *$ time after effect + error term,}

where time, effect and time after effect are defined as in the first model ; $\beta 6$ estimates the level of the sex ratio before the anticipated effect occurred (baseline level); $\beta 7$ estimates the change in sex ratio before the anticipated effect occurred; $\beta 6+\beta 8$ estimates the level of the sex ratio after the effect occurred; and $\beta 7+\beta 9$ estimates the change in sex ratio after the effect occurred.

\section{Patient and public involvement}

Patients were not involved in development of the research question and outcome measures, study design or conduct of this study.

\section{RESULTS}

Table 1 shows the sex ratio at delivery for all births in Ontario for each of the 12 months from the election onwards (from November 2016 to October 2017). During this time, the lowest seasonally adjusted sex ratio occurred in March 2017, which was 4 months after the election and thus precisely within the anticipated 3-5 months post-event interval. Figure 1 presents a time series of the seasonally adjusted sex ratio by month from April 2010 to October 2017, with predicted segmented regression lines shown for the following three intervals: before the election (from April 2010 to October 2016); from the election to before the anticipated effect (from November 2016 to February 2017); and from the anticipated effect to 5 months thereafter (from March 2017 to July 2017). This plot shows that the fall in the sex ratio in March 2017 was followed by a recovery in the 5 months thereafter, exhibiting the anticipated transient nature and time course of the predicted effect. Indeed, segmented regression analysis (table 2) confirmed that, compared with the period from the election to before the anticipated effect (from November 2016 to February 2017), the sex ratio was lower in the months from March 2017 to July 2017 ( $\beta 4=-0.0448$, $\mathrm{p}=0.02$ ). Moreover, the change in the sex ratio differed significantly in the period from March 2017 to July 2017 $(\beta 5=0.0133, \mathrm{p}=0.01)$, reflecting a rising slope in the latter interval (ie, recovery of the ratio). In contrast, neither the sex ratio nor the change therein differed significantly between pre-election and the post-election period before the anticipated effect (from November 2016 to February 2017). Thus, taken together, these data are indicative of a transient fall in the sex ratio 4 months after the election, with recovery in the 5 months thereafter.

To address the hypothesis that political preferences of the population may have affected the degree to which the unexpected outcome of the election was perceived as an adverse societal event and thereby contributed to the observed changes in the sex ratio, we classified each LHIN in Ontario as either liberal leaning or conservative leaning, based on the political party holding its constituent federal parliamentary ridings at the time of the US election. As shown in figure 2, the patterns of changes in the sex ratio differed markedly between liberalleaning and conservative-leaning regions. Indeed, in the liberal-leaning regions, the findings matched those observed in the entire population (table 2). Specifically, compared with the period from the election to before the anticipated effect, the post-effect interval from March 2017 to July 2017 showed a significantly lower sex ratio $(\beta 4=-0.0539, p=0.006)$, coupled with a rising slope $(\beta 5=0.0173, \mathrm{p}=0.002)$. In contrast, in the conservativeleaning regions (table 2), the analogous comparisons showed no significant differences in either the sex ratio $(\beta 4=0.0823, p=0.12)$ or the change therein $(\beta 5=-0.0103$, $\mathrm{p}=0.49)$. The same findings were observed when the analyses were limited to live births only (online supplementary table 1).

We also performed sensitivity analyses with two segments (before the anticipated effect and the post-effect interval) in two ways: by excluding the 3 months from December 2016 to February 2017, and by including these 3 months in the pre-effect segment (online supplementary table 2 ). With both approaches, the post-effect interval in the liberal-leaning regions showed a significantly lower sex ratio with a rising slope, while the conservative-leaning regions showed neither.

\section{DISCUSSION}

In this study, we demonstrate two main findings. First, Canada's most populous province experienced a decline in the sex ratio at birth 4 months after the 2016 US presidential election, with subsequent recovery in the 5 months thereafter. This time course of changes in the sex ratio matches that which has been previously described after adverse societal events, such as terrorist attacks. Second, the transient decline in the overall proportion of boys to girls born in Ontario in March 2017 was observed in politically liberal-leaning jurisdictions but not in conservativeleaning regions of the province. Taken together, these data suggest that the unanticipated outcome of the 2016 


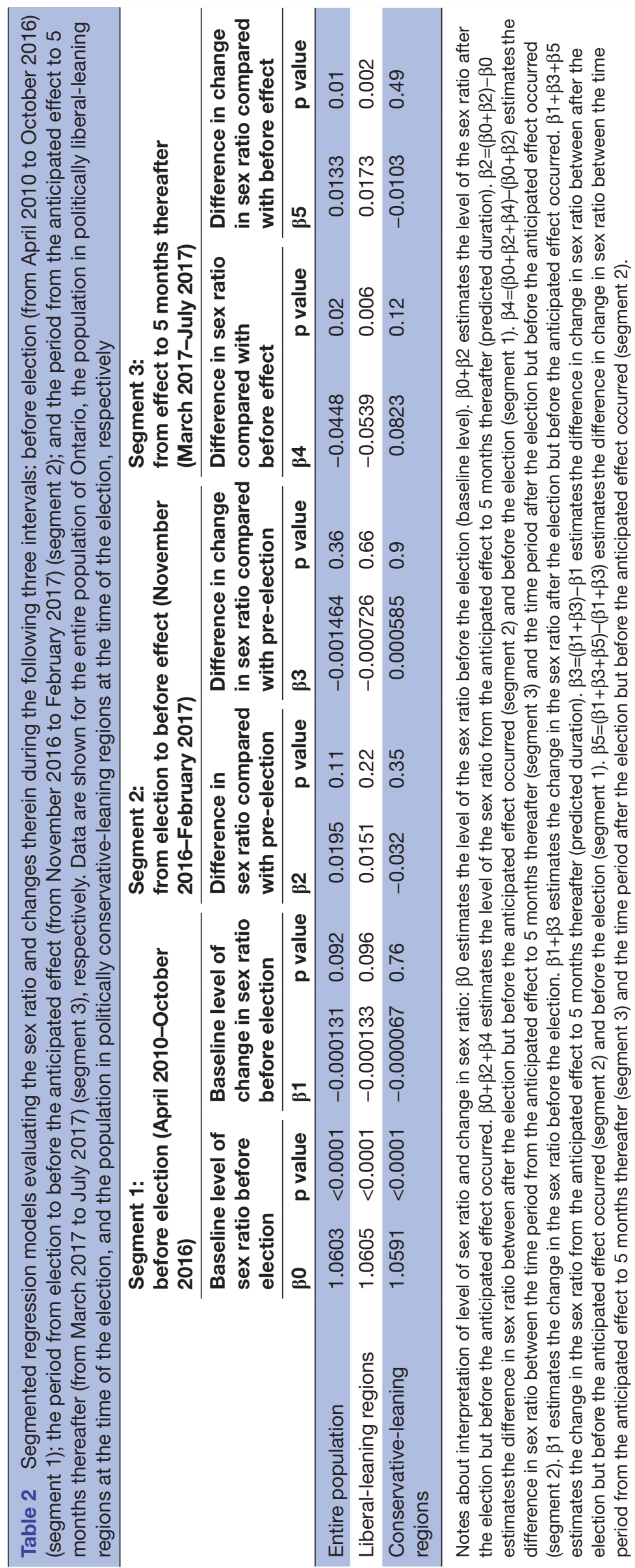



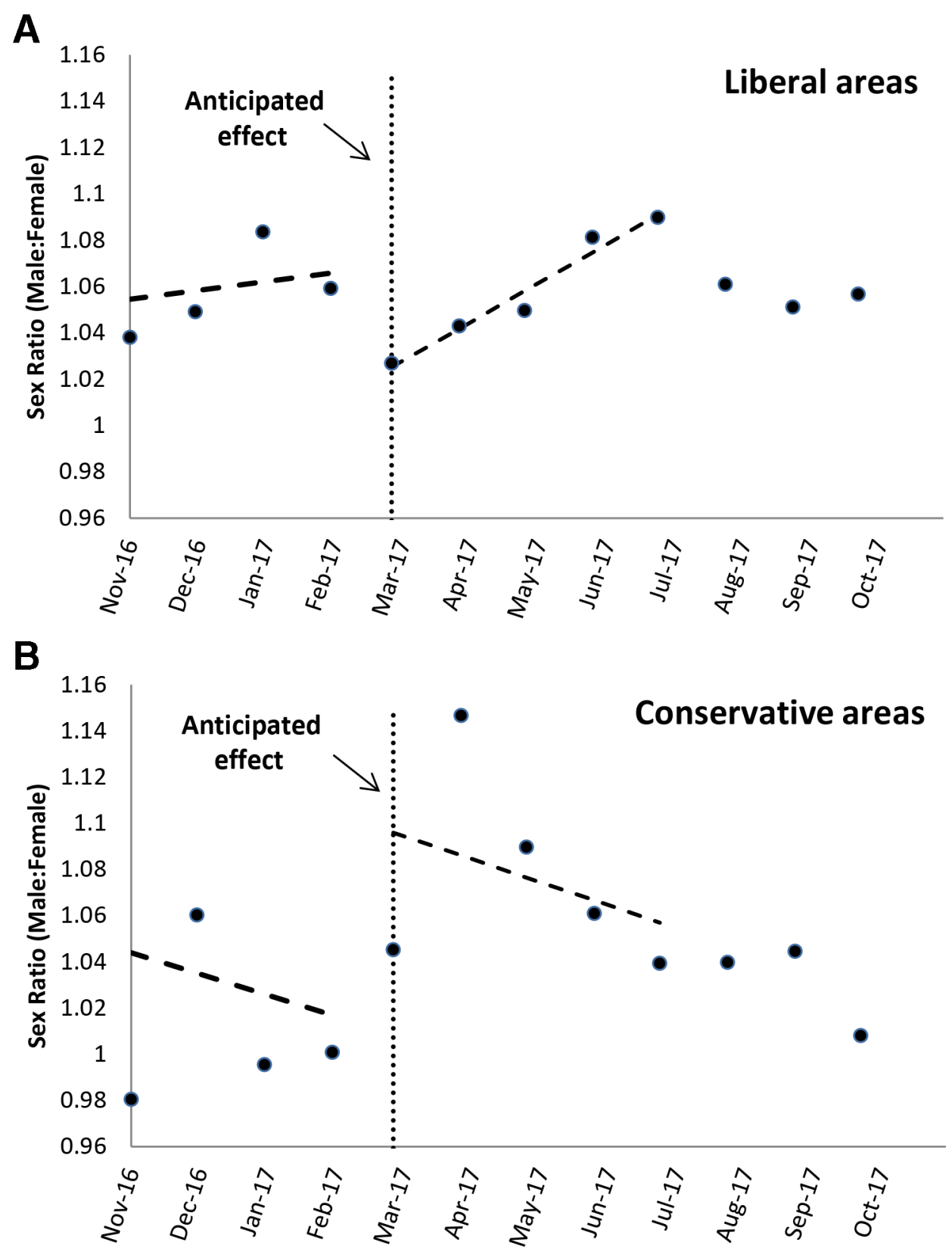

Figure 2 Time series of seasonally adjusted sex ratio by month from November 2016 (election) to October 2017 in (A) liberal-leaning regions and (B) conservative-leaning regions. Each panel shows the predicted regression line for the sex ratio for the period from the election to before the anticipated effect (from November 2016 to February 2017), and the period from anticipated effect to 5 months thereafter (from March 2017 to July 2017).

US presidential election was associated with a temporary reduction in the sex ratio at birth in Canada that may have related to its perception as an adverse societal event by the politically liberal-leaning population.

In humans, despite relative balance in the proportion of spermatozoa carrying a Y-chromosome to those carrying an X-chromosome, ${ }^{22}$ there is typically a slight preponderance of boys at delivery. This imbalance at birth has been attributed to sex-specific differences in fetal vulnerability during specific time periods in pregnancy. ${ }^{23}$ Indeed, after initial balance at conception, the sex ratio in humans varies at different timepoints across gestation, with total female mortality in utero ultimately exceeding male mortality (thereby yielding the slight excess of boys at delivery). ${ }^{23}$ Thus, changes in the sex ratio at birth can reflect the impact of sex-specific differences in fetal loss during pregnancy.

In this context, enhanced loss of male fetuses has been proposed as the mechanistic basis by which adverse societal stressors (such as disasters, terrorism and economic collapse) may lead to a reduction in the sex ratio at birth. ${ }^{356}$ From the perspective of evolutionary biology, it has been suggested that, under adverse conditions, the loss of frail male fetuses may be beneficial to the species by yielding a 'culled cohort' of healthier males that are better able to reproduce and hence increase the likelihood of survival 
of the population. ${ }^{5624}$ Among such societal stressors in humans, discrete events such as terrorist attacks have typically induced a characteristic pattern consisting of a transient decline in the sex ratio $3-5$ months later that is believed to reflect comparatively greater male fetal loss during a vulnerable window in mid-pregnancy at around 20-25 weeks' gestation. ${ }^{10}{ }^{17}$ In other words, the greater loss of male fetuses who are within this vulnerable window at the time of the event results in a depression of the sex ratio 3-5 months later when these babies would otherwise have been born. For example, after the terrorist attacks of September 11, 2001, the sex ratio fell 3-5 months later in New York, ${ }^{13}$ California ${ }^{14}$ and the entire US, ${ }^{15}$ accompanied by greater male fetal deaths in the intervening months. ${ }^{15}$ Indeed, this post-event loss of male babies has emerged as an under-recognised contributor to the overall casualty toll after terrorist attacks such as $9 / 11$, the 2011 Norway attacks, and the 2012 Sandy Hook Elementary School shooting. ${ }^{17}$

Against this background, we hypothesised that the unexpected victory of the nationalist, right-leaning Republican nominee in the 2016 US election and its resultant uncertain global implications could have been perceived as a societal stressor in left-leaning nations and thereby affected the sex ratio in a country such as Canada. Although we cannot definitively ascertain causality with the current study design, three lines of evidence arising from these data support this hypothesis. First, the hypothesised pattern of a transient decline in the sex ratio at birth followed by recovery thereafter was indeed observed in Ontario. Second, although other unrecognised societal factors may also affect the sex ratio, the anticipated decline occurred precisely within the predicted window of 3-5 months following the election, as did the recovery in the 5 months thereafter. Third, this effect was observed in liberal-leaning regions where the population may have perceived the outcome of the election as an adverse societal stressor, but not in conservative-leaning jurisdictions (where it may not have been perceived in this way). It is notable that the pattern of change in the sex ratio in the liberal regions precisely matched that which would occur after a discrete adverse event, with both the nadir 4 months post-election and continuous rise (recovery) over the 5 months that followed (figure $2 \mathrm{~A}$ and table 2). In contrast, the sex ratio pattern in conservative regions showed neither of these characteristic features (figure 2B and table 2).

We recognise that a limitation of this study is that population-level data provide limited capacity for inference to the level of the individual. Nevertheless, the ecological study design is appropriate for evaluating the impact of a societal stressor on a population outcome such as the sex ratio. ${ }^{25}$ Moreover, a strength of this study is its evaluation of all births in Ontario, such that the apparent differential post-election sex ratio pattern in the three conservative-leaning LHINs (in contrast to the 11 liberal-leaning LHINs) is not a reflection of limited power but instead indicative of some difference between the respective populations (though neither individual political preference nor the perception of stress in response to the election can be ascertained). Thus, limitations notwithstanding, we believe that the current data are collectively supportive of the hypothesis in question, owing to the precision of the predicted effect in both pattern and timing in both the entire provincial and politically stratified populations.

In summary, there was a decline in the proportion of boys to girls born in Canada's most populous province 4 months after the 2016 US presidential election followed by recovery in the 5 months thereafter, reflecting the characteristic pattern of changes observed after an adverse societal event. Moreover, this effect was observed in liberal-leaning jurisdictions of Ontario, but not in conservative-leaning regions. It thus emerges that the unanticipated outcome of the 2016 US presidential election may have held unrecognised implications for the populations of other countries, where its perception as a societal stressor may have impacted the sex ratio at birth in the months thereafter.

Acknowledgements RR holds the Boehringer Ingelheim Chair in Beta-cell Preservation, Function and Regeneration at Mount Sinai Hospital.

Contributors RR conceived the hypothesis. RR and CY designed the analysis plan. $\mathrm{CY}$ performed the analyses. RR wrote the manuscript. Both authors interpreted the data, critically revised the manuscript for important intellectual content, and approved the final manuscript. Both authors had full access to all of the data in the study and can take responsibility for the integrity of the data and the accuracy of the data analysis. The corresponding author attests that all listed authors meet authorship criteria and that no others meeting the criteria have been omitted.

Funding This study was supported by intramural funds from the Leadership Sinai Centre for Diabetes.

Disclaimer The funding source had no role in study design, data collection, data analysis, data interpretation, or writing of the report.

Competing interests Both authors have completed the ICMJE uniform disclosure form at www.icmje.org/coi_disclosure.pdf and declare: RR reports grants and personal fees from Novo Nordisk, grants from Boehringer Ingelheim, personal fees from Eli Lilly, personal fees from Takeda, personal fees from Sanofi, outside the submitted work.

Patient consent for publication Not required.

Ethics approval This study was approved by the Mount Sinai Hospital Research Ethics Board.

Provenance and peer review Not commissioned; externally peer reviewed.

Data availability statement Data may be obtained from a third party and are not publicly available. Data are available on request and permission from the Better Outcomes Registry \& Network (BORN) (www.bornontario.ca).

Open access This is an open access article distributed in accordance with the Creative Commons Attribution Non Commercial (CC BY-NC 4.0) license, which permits others to distribute, remix, adapt, build upon this work non-commercially, and license their derivative works on different terms, provided the original work is properly cited, appropriate credit is given, any changes made indicated, and the use is non-commercial. See: http://creativecommons.org/licenses/by-nc/4.0/.

ORCID iD

Ravi Retnakaran http://orcid.org/0000-0003-1989-027X

\section{REFERENCES}

1 Austad SN. The human prenatal sex ratio: a major surprise. Proc Natl Acad Sci U S A 2015;112:4839-40. 
2 Jacobsen R, Møller H, Mouritsen A. Natural variation in the human sex ratio. Hum Reprod 1999;14:3120-5.

3 James WH, Grech V. A review of the established and suspected causes of variations in human sex ratio at birth. Early Hum Dev 2017;109:50-6.

4 Retnakaran R, Wen SW, Tan H, et al. Maternal blood pressure before pregnancy and sex of the baby: a prospective preconception cohort study. Am J Hypertens 2017;30:hpw165-8.

5 Catalano R, Bruckner T. Secondary sex ratios and male lifespan: damaged or culled cohorts. Proc Natl Acad Sci U S A 2006;103:1639-43.

6 Bruckner T, Catalano R. The sex ratio and age-specific male mortality: evidence for culling in utero. Am J Hum Biol 2007;19:763-73.

7 Fukuda M, Fukuda K, Shimizu T, et al. Decline in sex ratio at birth after Kobe earthquake. Hum Reprod 1998;13:2321-2.

8 Catalano R, Yorifuji T, Kawachi I. Natural selection in utero: evidence from the great East Japan earthquake. Am J Hum Biol 2013;25:555-9.

9 Mocarelli P, Brambilla P, Gerthoux PM, et al. Change in sex ratio with exposure to dioxin. Lancet 1996;348:409.

10 Grech V, Zammit D. A review of terrorism and its reduction of the gender ratio at birth after seasonal adjustment. Early Hum Dev 2017;115:2-8.

11 Catalano R, Bruckner T, Anderson E, et al. Fetal death sex ratios: a test of the economic stress hypothesis. Int J Epidemio 2005;34:944-8

12 Grech V. The male-female birth ratio in California and the 1992 April riots in Los Angeles. West Indian Med J 2015;64:223-5.

13 Catalano R, Bruckner T, Marks AR, et al. Exogenous shocks to the human sex ratio: the case of September 11, 2001 in New York City. Hum Reprod 2006;21:3127-31.
14 Catalano R, Bruckner T, Gould J, et al. Sex ratios in California following the terrorist attacks of September 11, 2001. Hum Reprod 2005;20:1221-7.

15 Bruckner TA, Catalano R, Ahern J. Male fetal loss in the U.S. following the terrorist attacks of September 11, 2001. BMC Public Health 2010;10:273.

16 Grech V. Terrorist attacks and the male-to-female ratio at birth: the troubles in Northern Ireland, the Rodney King riots, and the Breivik and sandy hook shootings. Early Hum Dev 2015;91:837-40.

17 Masukume G, O'Neill SM, Khashan AS, et al. The terrorist attacks and the human live birth sex ratio: a systematic review and metaanalysis. Acta Medica 2017;60:59-65.

18 Lerchl A. Seasonality of sex ratio in Germany. Hum Reprod 1998;13:1401-2.

19 Gomez V, Maravall A. Guide for using the programs TRAMO and seats, beta version. Banco de España, 1997a.

20 Gomez V, Maravall A. Program TRAMO and seats: Instructions for the user, beta version. Banco de España, 1997b.

21 Penfold RB, Zhang F. Use of interrupted time series analysis in evaluating health care quality improvements. Acad Pediatr 2013;13:S38-44.

22 Boklage CE. The epigenetic environment: secondary sex ratio depends on differential survival in embryogenesis. Hum Reprod 2005;20:583-7.

23 Orzack SH, Stubblefield JW, Akmaev VR, et al. The human sex ratio from conception to birth. Proc Natl Acad Sci U S A 2015;112:E2102-11.

24 Trivers RL, Willard DE. Natural selection of parental ability to vary the sex ratio of offspring. Science 1973;179:90-2.

25 Pearce N. Epidemiology in a changing world: variation, causation and ubiquitous risk factors. Int J Epidemiol 2011;40:503-12. 